\title{
Una nueva vía de expresión plástica. El camino marcado por Miquel Mont y Xavier Escribà
}

A new source of plastic art research. The path marked by Miquel Mont and Xavier Escribà

Manuel Moreno

Resumen: A pesar de que algunos críticos e historiadores del arte anunciaran el fin de la pintura durante el siglo XX, las evidencias del buen estado en que se encuentra el medio han servido para expandir el significado de la pintura y sus posibilidades expresivas, ampliando los límites del medio y conjugando sus posibilidades plásticas con diferentes disciplinas sin ningún tipo de prejuicio. En este artículo nos acercamos a la obra de dos artistas que mantienen lazos estrechos con las ciudades de Barcelona y París, Xavier Escribà y Miquel Mont. Nuestro ánimo no es reflejar las coincidencias entre ambos autores sino reivindicar el carácter innovador que han demostrado con sus propias trayectorias.

Palabras clave: pintura, objeto, espacio, tridimensionalidad, proceso creativo.

Abstract: Although some art critics and historians predicted the end of painting during the 20th century, the evidence of the good state in which the medium is found has served to increase the meaning of painting and its expressive possibilities, expanding the limits of this field and combining it with different disciplines without any prejudice. In this article we approach the work of two artists who maintain close ties with the cities of Barcelona and Paris, Xavier Escribà and Miquel Mont. Our spirit is not to reflect the coincidences between the two artists but to claim the innovation of their own professional career

Key words: painting, object, space, three-dimensionality, creative process. 


\section{INTRODUCCIÓN: BAJO EL SIGNO DE ABBOTT}

A pesar de las diferencias que podemos encontrar entre las obras de Miquel Mont y Xavier Escribà, así como en sus trayectorias vitales, ambos artistas desarrollan nuevas soluciones en el campo de las artes plásticas y especialmente en el de la pintura. Quizá no hayan nacido bajo el signo de Saturno, condición a la que se refirieron el matrimonio Wittkower y también la novelista Susan Sontag, pero sí han encontrado en la evolución de sus pinturas-objetos el carácter que les distingue y reconoce como artistas, una circunstancia que bien podría ampararlos bajo el signo de Abbott.

La influencia de Saturno ha perseguido al gremio del arte durante siglos, atribuyéndole al artista unas cualidades especiales y un don mágico, acorde además a su espíritu independiente, melancólico y con frecuencia también maldito. Un estereotipo que a duras penas se mantiene hoy en día. Sin embargo, aún en la actualidad hay un buen grupo de artistas plásticos interesados en renovar el lenguaje visual y destruir las fronteras entre las distintas disciplinas, inquietudes que sin duda les acercarían al pensamiento nada común de Edwin A. Abbott. Este escritor británico publicó en 1884 una extraña novela titulada Planilandia, completamente experimental y exótica en su época, con la que inspiraría no solo a escritores sino también a matemáticos, físicos o astrónomos.

A nuestro juicio, tanto Mont como Escribà forman parte de este grupo de artistas de nuestro tiempo que, con su espíritu creativo e interés por la experimentación, reinventan los códigos del arte y consiguen romper las fórmulas convencionales. Más que una condición, partiendo de la ficticia atribución del signo de Abbott que hacemos en este escrito, se trata de una marca que les impulsaría a reinterpretar la historia del arte para proyectar la obra desde distintas perspectivas, siendo la supresión del bastidor unas de sus primeras decisiones.

La historia de Abbott no tiene una única lectura ya que, detrás del planteamiento geométrico de los mundos que crea, se pueden leer argumentos de crítica social o debates más cercanos a las ciencias sociales. El personaje principal es A. Square, un juego de palabras en la versión original con el que Abbott se refiere a la naturaleza del protagonista, tratándose de un elemento geométrico con forma de cuadrado. Planilandia es el nombre del mundo en el que habita A. Square, sirviendo como título de la novela y al mismo tiempo como postulado a partir del cual construir el resto de mundos y los distintos niveles de jerarquía. El fundamento que convierte a Planilandia en una obra de sumo interés es principalmente la inquietud que despierta en el lector, capacitándolo para cuestionar la realidad misma o animándolo al menos a valorar el enfoque crítico y el pensamiento divergente. Es mediante el contacto con otros mundos como el protagonista toma conciencia de su entorno, al igual que en el caso de nuestros dos artistas lo permite el acercamiento a otras áreas artísticas. Algo significativo ocurre cuando $\mathrm{A}$. Square, desde la óptica bidimensional que le confiere su mundo plano, se refiere al lector para admirar algunas de las cualidades de Espaciolandia, un mundo tridimensional que vendría a ser el equivalente al nuestro.

Es desde el punto estético y artístico cuando digo que nuestra vida es monótona; estética y artísticamente, ciertamente es muy aburrida.

¿Cómo podría ser de otra forma cuando todas las perspectivas del planilandés, la totalidad de los paisajes, piezas históricas, retratos, flores, nauturalezas muertas, se limitan a una simple línea sin matices e imprecisión ${ }^{1}$

Este sentimiento de inconformismo con la realidad podría recordarnos a ciertos aspectos atribuibles al espíritu saturnino. Susan Sontag dedicó una de sus extensas reflexiones a la figura de Walter Benjamin, al que describió como "nacido melancólico" y del que destacaba su habilidad y conocimiento para extraviarse en las ciudades. No solo lo explicaba el filósofo en sus notas biográficas, sino que además esta conciencia sutil con las urbes influiría en sus escritos y se convertiría en tema recurrente, como ocurrió de forma clara en Dirección única. Para Benjamin, la causa de su "profunda tristeza" tenía origen en Saturno, "la estrella de revolución más lenta, el planeta de las desviaciones y demoras....". Por el contrario, la característica que otorgaría nacer bajo el signo de Abbott sería la de buscar soluciones inesperadas y originales donde el resto solo vemos incertidumbres e incluso imposibilidades. Lucio Muñoz llamaba a este hecho "el chispazo" o "los dientes de sierra" ${ }^{2}$, y esta circunstancia es realmente destacable porque permite al artista adentrarse en caminos inexplorados. Como ejemplo podríamos tomar el caso de Rayuela, una obra cosida y descosida por Cortázar a través de la cual podemos analizar los entresijos de su construcción.

Desarmar una obra de teatro, una película, una pintura o una pieza conceptual puede resultar realmente estimulante para el espectador. Muchos acordaremos en que en ocasiones, las críticas y análisis vertidos sobre algunas obras pueden llegar a ser incluso más interesantes y enjundiosas que las propias creaciones artísticas, especialmente cuando nos descubren las proezas que no advertimos por nosotros mismos.

Uno de los grandes logros del arte moderno fue la reivindicación del medio plástico y el valor intrínseco del arte como medio expresivo. "Al fin y al cabo, si algo busca la pintura moderna es remarcar y no ocultar su carácter de pintura" ${ }^{3}$.

Volviendo de nuevo a Planilandia y sin desvelar sus vericuetos, podemos apreciar que una de sus principales virtudes y aportaciones, el interés por la conciencia de la realidad y el espacio, se vuelve a interpretar en otras voces como la del pintor Malévich, que llegó a escribir lo siguiente: "Me he convertido en el cero de la forma y me he rescatado del sucio cenagal del arte académico. He destruido el anillo del horizonte y me he salido del círculo de objetos, el anillo del horizonte que ha enjaulado al artista y a las formas de la naturaleza"4.

Durante los años 70 del siglo XX, que coincide con los primeros años de Mont y Escribà, una buena parte del mundo del arte "decidió declarar la pintura persona non grata, ante formas menos convencionales utilizadas por el conceptualismo, el arte antropológico, el minimalismo 1 Fragmento perteneciente al octavo capítulo, titulado: De l'antiga pràctica de la Pintura. Edwin A. Abbott. Planilàndia: Una novel.la de moltes dimensions. Traducció: Vidal i Tubau, J. Barcelona. Laertes de Ediciones. 2011. (Ediciones previas: Flatland: A romance in many dimensions, 1884, Harper Collins, 1983). 2 Muñoz utiliza estos términos con frecuencia en sus textos recogidos bajo el título, "El conejo en la chistera. Escritos del artista". Lucio Muñoz. El conejo en la chistera. Escritos del artista. Madrid. Editorial Sintesis, 2006.

3 BARRO, David: Un puñado de razones de por qué la pintura no se secó. En: On painting: prácticas pictóricas actuales más allá de la pintura o más acá. Proyecto y comisariado general de Omar Pascual Castillo. Las Palmas de Gran Canaria: CAAM Centro Atlántico de Arte Moderno. 2013. p.161 $4 \quad$ MALEVICH, Kazimir: Suprematism. Incluido en Suprematizm, 34 risunka, UNOVIS, Vitebsk, 1920. EL PÁJARO DE BENÍN 6 (2020), págs. 9-21. ISSN 2530-9536 
y un largo etcétera" ${ }^{5}$.

Para entonces muchos pintores ya llevaban años experimentando con el propio lenguaje de la materia, como era el caso de Tàpies, Auerbach, Kiefer, Cuixart, Schwitters, Millares o Rauschenberg entre otros. El impacto que estos artistas ejercerían sobre las nuevas generaciones permitió que se desarrollaran propuestas alternativas y novedosas. Una de las proyecciones más internacionales fue la de Ángela de la Cruz, a la que podríamos considerar como una de las pioneras de la llamada pintura expandida, junto a otros nombres como Lisa Sigal, María Luisa Fernández o Jessica Stockholder. Las incisiones de Lucio Fontana han significado en la historia de la pintura un punto de inflexión muy claro, a partir del cual creadores como la gallega Ángela de la Cruz se han decantado por la vía interdisciplinar. La comisaria Carolina Grau escribió lo siguiente con motivo de su exposición "Ángela de la Cruz. Escombros".

En el caso de la obra de Ángela de la Cruz, su motor es continuar cuestionando los límites de la pintura y la escultura, utilizando indistintamente un medio u otro según lo que desee expresar y la necesidad de cada obra. Como ella misma ha dicho, "es una escultura utilizando el lenguaje de la pintura y viceversa, es una pintura y una escultura". En estos últimos cinco años, De la Cruz ha evolucionado en su lenguaje; donde antes predominaba la pintura situada en cualquier parte del espacio -en el suelo o en las esquinas-, ahora encontramos que el uso del aluminio y su elascticidad le han proporcionado libertad a sus esculturas para ser instaladas en cualquier parte del espacio expositivo ${ }^{6}$.

Clement Greenberg aseguraba que "para conseguir la autonomía, la pintura debe, por encima de todo, despojarse de todo aquello que pueda compartir con la escultura" ${ }^{\prime 7}$. Si atendemos al transcurso de los acontecimientos, podemos darle la razón a Greenberg en cuanto a que los límites entre las distintas disciplinas se han disuelto, al menos en el modo en que se habían definido hasta entonces la pintura o la escultura. Por otro lado, ¿̇se puede decir que la pintura perdiera potestad con la aparición de la fotografía? Quizá la única condición que mantenga la pintura vigente sea su capacidad de transformación, después de todo, si lo que se pretende es conseguir la autonomía de la pintura debería ser suficiente si atendiéramos exclusivamente a su poder de adaptación.

En la línea de Greenberg se encuentra también el siguiente comentario de Simón Marchán, en el que defiende que "la Nueva Abstracción considera por esto mismo a la pintura como un género camino de la agonía y con soluciones muy restringidas. El empleo del shaped canvas

DE LA NUÉZ, Iván: Inundaciones. Del muro a Guantánamo: Invasiones artísticas en las fronteras políticas 1989-2009. Barcelona. Editorial Debate, 2009. p.98 6 Texto del catálogo de la exposición "Ángela de Cruz.

Escombros".

Disponible en: $w w w$.lapanera.cat $/$ home.php?op=10\&module=programacio\&cad=2\&item $=172$ [Consulta: 4 de octubre de 2019].

GREENBERG, Clement: La pintura moderna y otros ensayos. Madrid. Ed. Félix Fanés. Ediciones Suriela. 2006. p.114 en vez del clásico soporte, no hace más que prolongar su agonía"8. Si confiamos en este diagnóstico, a pesar de que la pintura lleve muriendo al menos desde $1915^{9}$, deberíamos poder ver esta realidad también en galerías y ferias de arte. Desafortunadamente, resulta fácil comprobar las pocas exposiciones que se dedican a la pintura hoy en día, pero esto no implica que la calidad y el valor de la pintura hayan desaparecido. Existen pintores como Escribà, Guillermo Mora, Irene Grau, Mont o Silvia Lerín, que siguiendo la estela de Abbott, apuestan por vertientes inexploradas.

\section{LA PIEL DE LA PINTURA. XAVIER ESCRIBÀ}

Es difícil pensar cómo y por qué Escribà inicia esta reflexión (sobre la ruptura con el bastidor del lienzo). Seguramente no haya una única explicación y las razones profundas se nos escapen, pero en su trayectoria intuimos un punto de partida: el monocromo titulado Barcelona París [Aller-Retour], del ya lejano 1993. Se trata de una pieza taladrada y con el bastidor aún visible entre los orificios, totalmente dislocado. A primera vista, podría pasar por un experimento más de aquellos que se almacenan olvidados en el estudio de los artistas. No obstante, a nuestro parecer resultan de gran importancia, ya que se trata de la primera vez -que sepamos-, que el pintor ataca el formato, esto es, que desgarra la pintura ${ }^{10}$.

El taller de Escribà (París, 1969) no es solo el espacio donde germinaron muchas de sus ideas y proyectos. Significa también un estado del arte donde los ritmos de producción, investigación y reflexión se suceden continuamente, siendo como es natural el lugar físico donde realizar sus obras. El proceso creativo para Escribà no es más que una tarea corriente, un ejercicio diario que muestra al público con frecuencia sin el menor pudor o recelo. "Yo lo vivo como una cosa cotidiana porque para mí no tiene misterio hacer esto. Si haces pintura, escultura, música o cirugía, es un trabajo diario...es una práctica cotidiana" ${ }^{11}$. Este tipo de reflexión, con más o menos efecto, permite al público en general familiarizarse con el trabajo del pintor, ayudando ya de paso a desmitificar esta idea saturnina del artista melancólico o lleno de rarezas. Sus exposiciones en muchas ocasiones han ido precedidas por la apertura de su taller a escuelas o público en general; como el Taller Obert en Girona (2008), Taller en Trànsit (Tarragona, 2011), El suport de la pintura (Cardedeu, 2012) o Espai + Temps (Ripoll, 2015).

No siempre sus proyectos parten de ideas concebidas en el estudio, pero en cualquier caso, el lugar en el que se encuentra trabajando ejerce un papel trascendental en el proceso

8 MARCHÁN, Simón: Del arte objetual al arte de concepto. Madrid. Akal. 2001. P.92

9 Hacemos este acta de defunción teniendo en cuenta el año de creación de la obra considerada por muchos como el Harakiri de la propia pintura, el "cuadrado negro sobre fondo blanco" de Malévich.

10 Texto de Jaume Vidal Oliveras en el catálogo de la muestra "La Face «au culte» de la peinture",

exposición individual de Xavier Escribà en la Galería D'Art Oriol, del 16 de junio al 28 de julio de 2011.

11 Transcripción del documental realizado por Meritxell Collazos en 2008, con ocasión del Taller Obert de Escribà en la Casa de la Cultura de Girona. Disponible en: https://vimeo.com/23117880 [Consulta: 5 de octubre de 2019].

EL PÁJARO DE BENÍN 6 (2020), págs. 9-21. ISSN 2530-9536 


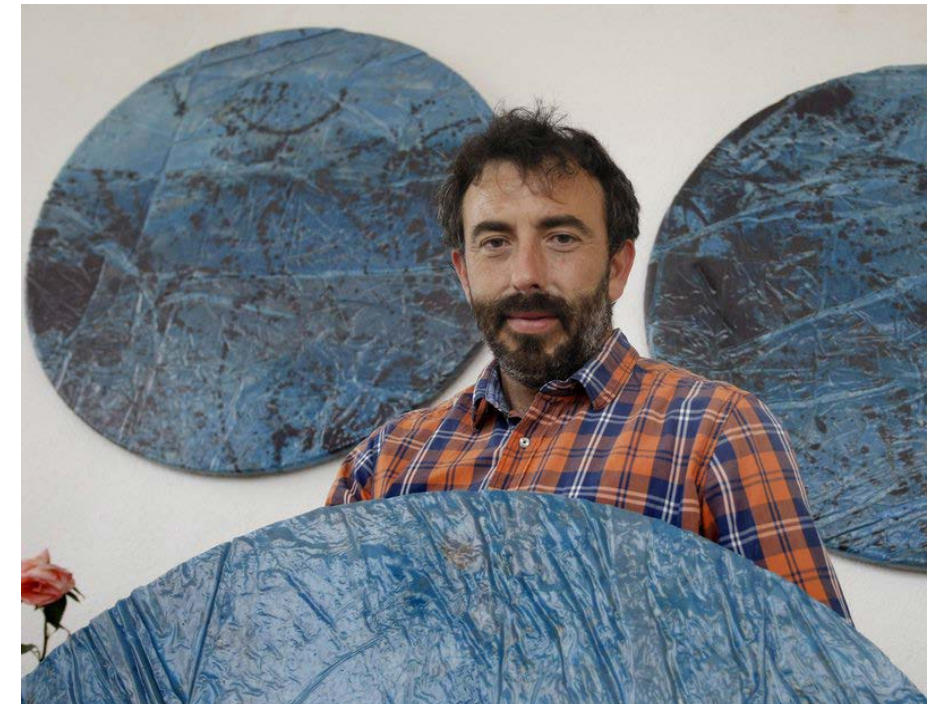

Xavier Escribà junto a su obra, L'Heure Bleue (2012)

huevas y excepcionales condiciones que le aportaba

consecuentemente en el resultado. De entre todos sus proyectos queremos referirnos a L'Heure Bleue (fig. 1), realizado en 2012 en el municipio de Sant Martíd'Empùries. Escribà resultó ganador de la XIV Edición de la Beca Internacional de Primavera de Artes Plásticas de Ayuntamiento de L'Escala (Girona), lo que le permitió trabajar durante tres meses en la Casa Forestal del municipio gerundense. Según sus propias palabras, "El paisatge era tan impressionant que vaig haver d'alliverar-me de l'obligació de fer obra tal i com l'havia fet fins ara"12. El acierto del pintor fue adaptarse a las

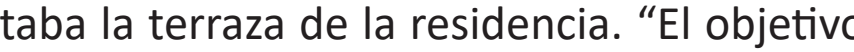
de Xavier Escribà era convertir la terraza de su residencia -de cara al mar- en la cubierta de un barco atrapado entre dos grandes azules. Asumido su papel de Ulises solitario, tan solo le quedaba al artista acotar los periodos de su acción ${ }^{13 \prime \prime}$.

Para Cézanne, la montaña de Saint-Victoire no era en sí misma un tema en el que trabajar hasta la saciedad, lo que le importaba en realidad era poder sacar conclusiones que le ayudaran a construir una "totalidad" a partir de fragmentos reales de la montaña. Más que obtener un parecido físico de la realidad, lo que le obsesionaba era la propia autonomía de la pintura y el modo en que debía dominar el espacio del cuadro. Como en muchos de los procesos del arte contemporáneo, donde los artistas se autoimponen unas normas o pautas a seguir, Escribà condicionó su proyecto a algunos de los ritmos naturales que le animaban a trabajar en momentos específicos del día. El hecho de llevar su taller a la terraza de la Casa Forestal le permitió liberarse de algunos condicionamientos como pueden ser el bastidor o los límites fronterizos entre el exterior y el interior. Todo quedaba en L'Heure Bleue de una manera abierta, en un contexto que se le presentaba en completa expansión.

Si bien su proceso artístico está secundado o acondicionado por los ritmos naturales (tiempos de secado, superposición de capas, referencias lumínicas del lugar, etc.), no es menos importante la referencia que del ritmo vital hace el autor, ya que en sus obras es habitual encontrar aspectos que señalan su edad. Una de sus muestras más destacables hasta el momento, por emblemática y ambiciosa, es la que llevó a cabo en la galería Marc Domènech en octubre de 2016, cuyo título fue D'on venim, on som (fig. 2). Escribà hizo uso de los espacios de la galería con una sola estructura tridimensional que conectaba unas salas con otras, volviendo a explotar las posibilidades de la pintura a través de su conjugación sobre fragmentos de hierro. La muestra tuvo una duración de 47 días, una voluntad que coincidía con las diferentes fases de la obra y por supuesto con la edad del pintor. Hasta entonces Escribà había desarrollado unos procedimientos sencillos y originales que le permitían

12 El Mirall de L'Heure Bleue [Catálogo de la exposición]: Història d'un procés creatiu / Xavier Escribà; [Texts catáleg: Cristina Masanés, Clarie Cayla]. Figueres, Museo de Empordà. 2015

13 Observaciones del artista y comisario Eudald Camps en su blog titulado Memòria i descampat, el cual recomendamos encarecidamente. manejar la pintura como un material consistente y flexible, idóneo para conseguir resultados más corpóreos y tridimensionales. Su fin, concebirlos como presencias con autonomía propia. La acción que definía su proceso era el de la acumulación de capas de pintura acrílica sobre la superficie del suelo, tratándose en el caso de L'Heure Bleue de pequeñas variaciones entre unas y otras piezas. Una vez que éstas se secaban por completo, como si fuesen sustratos o epidermis, recortaba el material para aprovechar su maleabilidad.

A diferencia de este procedimiento, la obra que expuso en la galería Marc Domènech se llevó a cabo a través de la acumulación de pintura sobre piezas de hierro. Según Anna-María Guasch, la obra no era "sólo una clara transgresión a la autonomía de lenguajes, sino una buscada carnosidad de la pintura, y una alusión al paso del tiempo, que es el suyo"14.

En cierta manera, esta obra de Escribà puede recordarnos a la que realizó Barceló para la Cúpula de la Sala de los Derechos Humanos de la ONU. Mediante la superposición de pintura acrílica obtenía una suerte de dripping tridimensional con resonancia biográfica y del que subrayaba Sònia Hernández lo siguiente: "ha construido una línea de la vida flotante en la que, por el contrario, capas de pintura que funcionan como epidermis van cubriendo la superficie según pasan los años. Así, un tubo de hierro acerado de 95,3 metros que recorre, suspendido, las paredes de la galería sirve como autorretrato abstracto del artista. [...] las capas de acrílico y pigmento se acumulan y forman, en lugar de arrugas, estalactitas"15. Sin duda, hay muchos aspectos en la obra de Escribà que se han convertido en constantes, como la transformación de la pintura o la propias lecturas biográficas que nos deja entrever el pintor, pero quizá lo más destacable sea el uso que del oficio artístico ha hecho Xavier para tratar el material como un ente con forma propia y piel mutable.

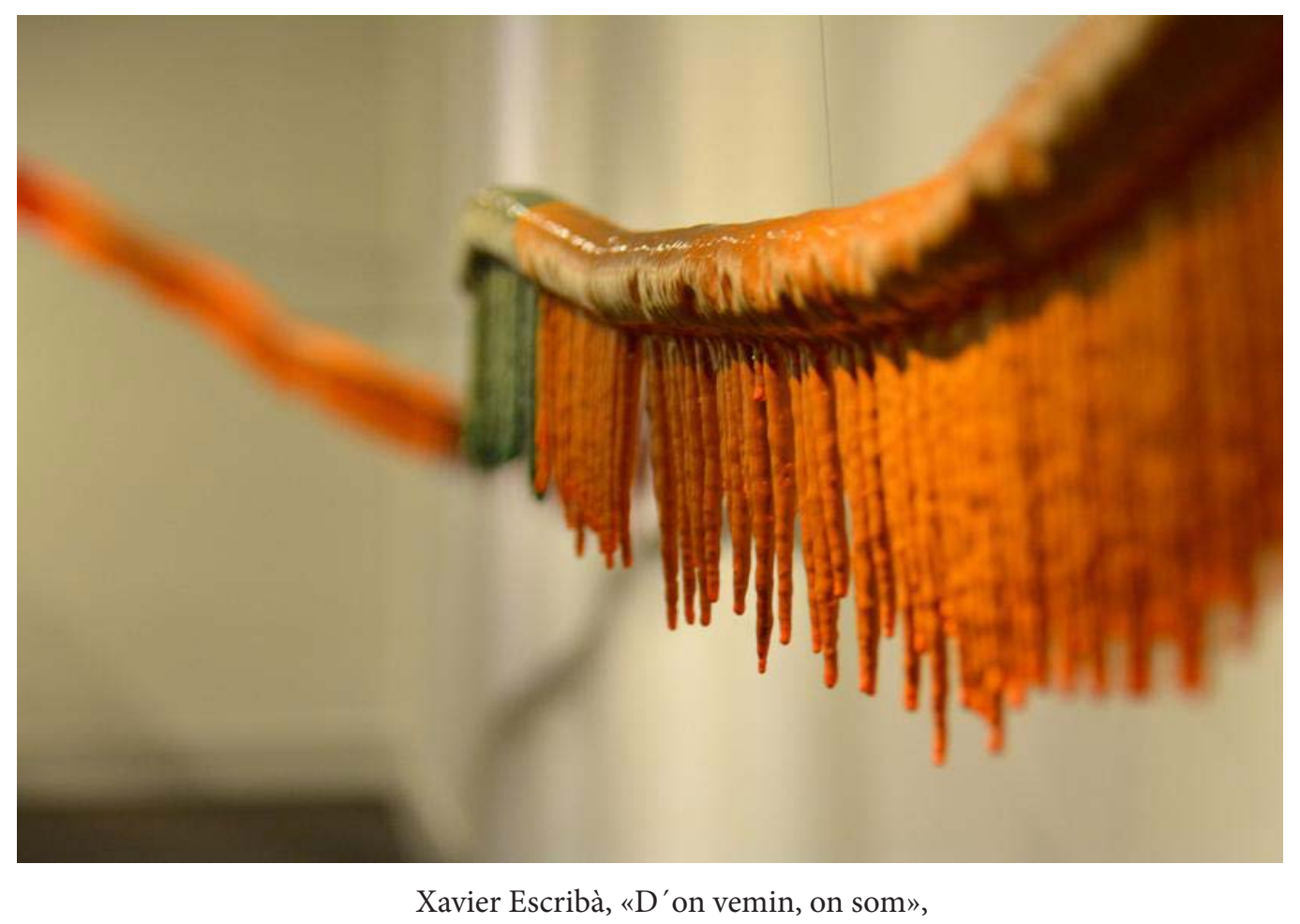

2016

14 GUASCH, Anna-María: Barcelona vuelve a la carrera. En: ABC Cultural. 8 de octubre de 2016. p. 23 15 HERNÁNDEZ, Sonia: Una vida por capas. En: La Vanguardia. 22 de octubre de 2016.

EL PÁJARO DE BENÍN 6 (2020), págs. 9-21. ISSN 2530-9536 


\section{LA EMANCIPACIÓN DE LA PINTURA. MIQUEL MONT}

En una de las publicaciones más aplaudidas de Carlos Marzal, El cuaderno del polizón, encontramos un capítulo un tanto desconcertante dedicado a la naturaleza silente y "animista" del mobiliario. Bajo el epígrafe de Bestiario mueble, Marzal desarrolla una reflexión acerca de los objetos cotidianos y la posibilidad de que éstos contengan parte de la historia del lugar en el que se han encontrado. Más allá del deslizamiento poético que hace de algunos de los lugares de confort, el escritor desemboca en algunas ideas que nos parecen adecuadas para describir el trabajo de Miquel Mont (Barcelona, 1963). "Reducir la materia a su expresión primaria, requiere un esfuerzo esclavo, ya que la Primera Ley de la gravitación objetual indica que las cosas, por sí solas, tienden a su acumulación, acaparan el espacio. Los trastos innecesarios no se crean ni se destruyen, sino que sólo se transforman a nuestro alrededor"16.

De entre todas las vanguardias, la que probablemente influyó en mayor medida en Miquel Mont fue la del grupo Supports-surfaces a finales de los años 60, movimiento francés liderado por Vincent Bioulès. Para los también conocidos como nuevos reduccionistas la pintura debía entenderse como un hecho plástico con validez en sí misma y desprovista de cualquier expresión o proyecciones conceptuales.

Esta neutralidad ha quedado como poso en la obra del artista catalán, a pesar de que la evolución de su trabajo ha generado nuevas direcciones en sus propios proyectos. Una de las primeras claves a las que nos deberíamos referir es la pauta, la pauta entendida como proposición. Al igual que en la pulcritud de artistas como Donald Judd o Lewitt, Mont se propuso ya desde su serie Lapsus algunas exigencias técnicas y formales que determinarían los resultados posteriores en gran medida. Todas sus obras, pertenecientes a series donde se inscriben cada una de ellas, se desarrollan a partir de planteamientos precisos como si se trataran de partituras. "Cada proyecto determina el medio de la obra, el tipo de objeto, sus dimensiones, la manera en que se aplica el color o la manera en que es presentada $y^{\prime \prime}{ }^{17}$.

Durante los años 80 y 90 Mont empieza a decantarse por una pintura muy densa, apropiada en una época y en una ciudad como Barcelona donde el Neo-expresionismo y la Transvanguardia estaban en boga, especialmente entre los estudiantes y en los ambientes agitadores más propios de la contracultura y la música punk. El factor común que hacía converger a pintores de diversa índole era el descontento y sus pretensiones por liberar la pintura y el arte en general de toda norma.

La verdadera revelación le llegaría a Mont con su segunda exposición en la galería de Carles Poy, en 1991. Enrique Juncosa advertía "cambios notables en la evolución de su quehacer artístico. Si en su primer contacto con el público,

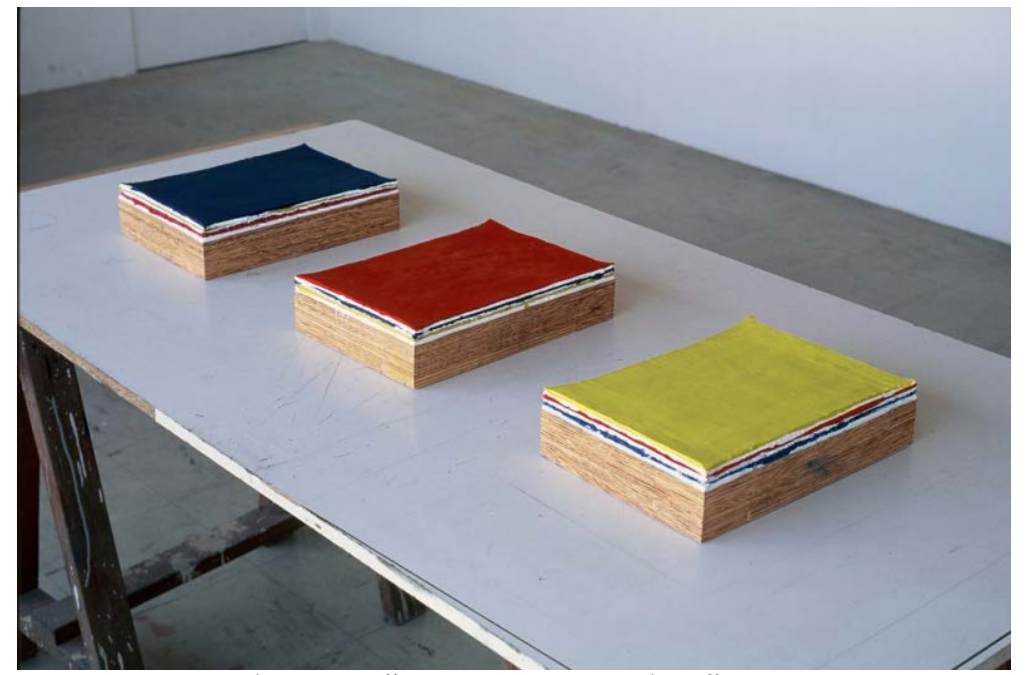

Miquel Mont, "Peintures empilées", 1990

16 MARZAL, Carlos: El cuaderno del polizón. Apuntes sobre Arte. Valencia, Pre-textos. 2007. p. 126 17 Rosa Queralt i Miquel Mont. Snippets of a Conversation.

Disponible en: http://miquelmont.net/?p=891\&lang=en. [Consulta: 8 de octubre de 2019] 
Miquel Mont flirteaba con la escultura desde la pintura misma -al embadurnar de látex y pigmentos construcciones tridimensionales de madera-, en esta nueva exposición Mont presenta, sin complejos, pinturas realizadas sobre maderas mucho más delgadas y, en su mayoría, directamente sobre lienzo"18. El artista, que ya llevaba viviendo en París dos años antes de esta muestra, había conseguido establecer una serie de códigos que se convertirían a través de los años en indicadores de su propio lenguaje artístico. Para Rosa Olivares, la exposición en Carles Poy significaba "una evolución propia del joven que investiga nuevos caminos, que retoma sus anteriores logros, que, en definitiva, trabaja hacia dentro de su experiencia artística, más interesado en principio en los aspectos formales, en la estructura lingüística de la obra que en el desarrollo de los conceptos más esotéricos"19.

Otro de los aspectos reconocibles en la obra de Miquel Mont es la dualidad entre el formalismo de sus obras y la concepción intelectual. La pintura como material le resultaba imprescindible, conjugándolas con materiales más o menos convenciones como telas, pladur o tableros de madera que externamente le ayudaban a trabajar con mayor volumen. La pintura no era solamente el denominador común porque hiciera uso del látex o el color, lo era esencialmente por su formalismo estructural y su evocación de conceptos como la simetría, los campos contrarios, la tensión o el equilibrio.

En estas primeras obras el acento estaba claramente en los procesos mismos de creación siendo visibles sus conexiones con las vanguardias desde el automatismo a la abstracción-. postpictórica. "Se trata de pinturas abstractas que se resuelven por sí mismas con una intervención mínima por parte de su creador"

Painting is a physical and material act. You can't paint without material. You can paint metaphorically-something we've seen a lot in recent years-but it works metaphorically precisely because we have the physical presence of painting at the back of our mind. This material quality of painting has always fascinated me and I can't disassociate it from my experience with art. And the opposing side is the need for a mental territory, a field of work where this material can take shape and take on meaning. Those early paintings already contained that seed, an intuition that painting was material and needed to seek out mental spaces ${ }^{21}$.

Su inclinación por los procedimientos pictóricos más densos y expresivos seguirá intacto a otros niveles de concepción, como veríamos más tarde en exposiciones como la realizada en 2016 en la galería Formato Cómodo de Madrid. Si en su muestra de 1991 dábamos cuenta de la expansión volumétrica de las obras y sus primeros ensayos sobre las paredes de la sala, años después los propios muros de las salas de exposición se convertirían en partes intrínsecas de sus pinturas. Las proposiciones de Mont, en el momento en el que amplía los límites de la pintura haciendo uso de los paramentos, vinieron dadas por su interés en acercar

18 JUNCOSA, Enrique: Los pigmentos plastificados de Mont. En: El País. 22 de febrero de 1993.

19 OLIVARES, Rosa: Miquel Mont. En: Lápiz. Revista Internacional de Arte. no76. 1991. p. 90

20 JUNCOSA, Enrique: op. cit.

21 Rosa Queralt i Miquel Mont. op. cit. la superficie de las paredes con los materiales industriales con los que acostumbra a trabajar.

No nos resulta nada extraño, lo que por otro lado parece inevitable, que finalmente en 2015 coincidieran en una misma muestra los trabajos de Miquel Mont y Guillermo Mora22, evidenciando de esta manera la continua expansión de la pintura y el relevo con los jóvenes creadores.

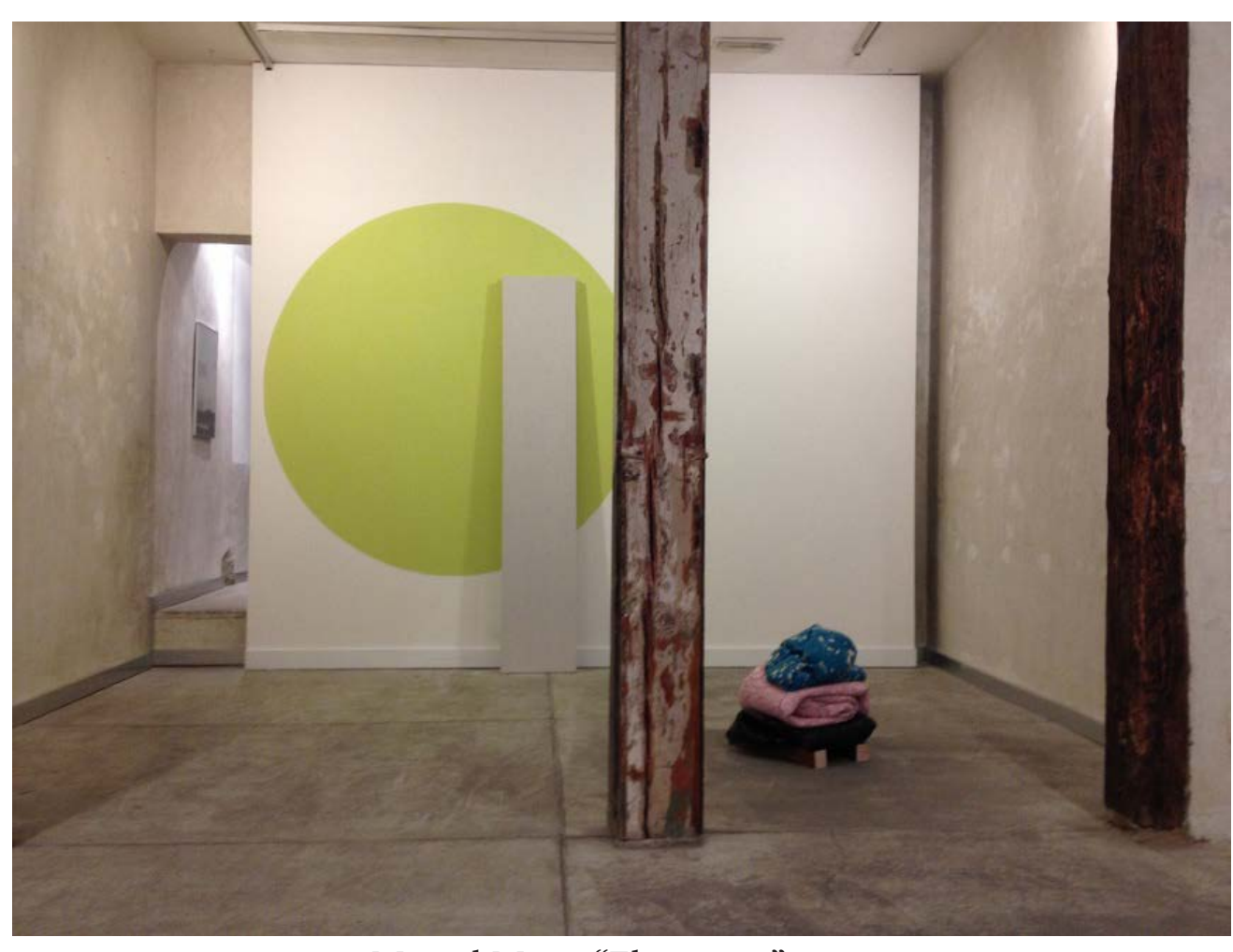

Miquel Mont, "El ojo toca”, 2015

\section{NOTAS DE CONCLUSIÓN}

Las contrastadas trayectorias de Xavier Escribà y Miquel Mont nos sirven para evidenciar la constante apertura del lenguaje pictórico aún en la actualidad. La renovación continua de los códigos tradicionales, así como la asimilación de las vanguardias que estos dos artistas han demostrado durante más de dos décadas, hacen posible que un medio expresivo como la pintura siga expandiendo sus límites a través de nuevas soluciones espaciales. El conocimiento que tienen estos dos pintores de los discursos más conceptuales y teóricos, unidos éstos a su extenso conocimiento del formalismo pictórico, han dejado una huella profunda en las nuevas generaciones y especialmente en los jóvenes artistas.

Al comenzar este escrito nos referimos a un escritor como Abbott con la intención de que se entendiera la magnitud del propósito que se marcaron ambos pintores al inicio de sus carreras artísticas. La visionaria y compleja propuesta de Abbott podría tener su réplica en estos dos pintores que, a través de sus continuas investigaciones y proposiciones, no han cesado de reinterpretar una y otra vez las múltiples lecturas que de la pintura podemos hacer.

22 La muestra se llevó a cabo en la galería Formato Cómodo, bajo el título de El ojo toca. Madrid EL PÁJARO DE BENÍN 6 (2020), págs. 9-21. ISSN 2530-9536 


\section{BIBLIOGRAFÍA}

ABBOTT ABBOTT, Edwin (2011). Planilàndia: Una novel·la de moltes dimensions. Traducción: Vidal i Tubau, J. Barcelona. Laertes de Ediciones. (Ediciones previas: Flatland: A romance in many dimensions, 1884, Harper Collins, 1983).

BARRO. David (2013) Un puñado de razones de por qué la pintura no se secó. En: On painting: prácticas pictóricas actuales... más allá de la pintura o más acá. Proyecto comisariado por Omar Pascual Castillo. Las Palmas de Gran Canaria: CAAM Centro Atlántico de Arte Moderno.

CAMP, Eudald (2012) Memòria i descampat. Disponible en: https://eudaldcamps. com/2012/06/25/Ihora-blava-de-xavier-escriba/ [Consulta: 3 de octubre de 2019]

COLLAZOS. Meritxel (2008) Transcripción del documental realizado en 2008 con ocasión del Taller Abierto de Escribà en la Casa de la Cultura de Girona. Disponible en: https://vimeo. com/23117880 [Consulta: 5 de octubre de 2019].

DE LA NUEZ, Iván (2009) Inundaciones. Del muro a Guantánamo: Invasiones artísticas en las fronteras políticas 1989-2009. Barcelona. Editorial Debate.

ESCRIBÀ, Xavier (2015) El Mirall de L'Heure Bleue [Catálogo de la exposición]: Història d'un procés creatiu / Xavier Escribà; [Textos del catálogo: Cristina Masanés, Clarie Cayla]. Figueres, Museo de Empordà.

GRAU. Carolina (2016) Ángela de Cruz. Escombros. Disponible en: www.lapanera.cat/home. php?op=10\&module=programacio \&cad=2\&item=172 [Consulta: 16 de octubre de 2019].

GREENBERG, Clement (2006) La pintura moderna y otros ensayos. Ed. Félix Fanés. Madrid. Ediciones Siruela.

GUASCH, Anna-María (2016) Barcelona vuelve a la carrera. En: ABC Cultural. 8 de octubre de 2016.

HERNÁNDEZ, Sònia (2016) Una vida por capas. En: La Vanguardia. 22 de octubre de 2016.

JUNCOSA, Enrique (1993) Los pigmentos plastificados de Mont. En: El País. 22 de febrero de 1993.

MALÉVIC, Kazimir (1920) Suprematismo, incluido en Suprematizm, 34 risunka, UNOVIS, Vitebsk.

MARCHÁN, Simón (2001) Del arte objetual al arte de concepto. Madrid. Akal.

MARTínEZ, A. (2000) Miquel Mont. El lugar de la pintura o la presencia de lo real. En: DC PAPERS, revista de crítica y teoría de la arquitectura. №4.

MARZAL, Carlos (2007) El cuaderno del polizón. Apuntes sobre Arte. Valencia, Pre-textos.

MUÑOZ, Lucio (2006) El conejo en la chistera. Escritos del artista. Madrid. Editorial Síntesis.

OLIVARES, Rosa (1991) Miquel Mont. En: Lápiz. Revista Internacional de Arte. no76.

QUERALT, Rosa (2008) Snippets of a Conversation. Disponible en: http://miquelmont. net/?p=891\&lang=en. [Consulta: 8 de octubre de 2019].

VIDAL OLIVARES, Jaume (2011) Catálogo de la muestra "La Face "au culte» de la peinture", exposición individual de Xavier Escribà en la Galería D’Art Oriol, del 16 de junio al 28 de julio de 2011. 